\title{
ANALYSIS OF THE OUTCOME OF MEDICAL TREATMENT AND COLD ABSCESS DRAINAGE OF SPINAL TUBERCULOSIS. EXPERIENCE OF 51 CASES IN NEUROSURGERY UNIT.
}

\author{
ALI HAIDER', SAIMA ${ }^{2}$, GOHAR ALI $^{3}$, ZIA REHMAN $^{4}$ \\ 1,3,4. Department of Neurosurgery LRH, PGMI, Peshawar. \\ 2. PhD student department of microbiology \& biotechnology university of Peshawar.
}

\begin{abstract}
OBJECTIVES: Laparoscopic surgery is well established in general patients but its safety and efficacy in pregnant patients is still debated especially in emergency situation.

METHODS: This study was conducted at Rai Medical Complex, Sargodha as prospective single centre study for all pregnant patients in need of laparoscopic appendectomy and cholecystectomy for acute appendicitis and acute cholecystitis respectively from April 2009 to December, 2011. After routine preoperative assessment, all were operated under general anesthesia with antibiotic cover, foure port technique for lap. chole. And three port technique for lap. appendectomy were used. Peri-operative morbidity and mortality for the mother and fetus were evaluated at Rai Medical Complex, Sargodha from 2009 to 2011.
\end{abstract}

RESULTS: 32 patients underwent laparoscopic procedures. 18 had laparoscopic cholecystectomy and 14 laparoscopic appendectomies. No maternal death and no loss of fetus.

CONCLUSION: Laparoscopic cholecystectomy and appendectomy appears to be as safe as in open surgery in pregnant women.

\section{INTRODUCTION}

The history of tuberculosis (TB) goes back to 5000 B.C. Sir Percivel Pott in 1782 for the first time described the painful kyphotic deformity of spine $^{1,2,3}$. TB is a great problem in developing countries and now in developed countries also due to immune compromised patients. $1 / 3$ of world population has TB bacilli in the system, only 16 million have the disease. In Pakistan there are 2.8 million patients and one Lac are added each year. About $1-5 \%$ of TB patients develop spinal TB. Laennec (1781-1826) the French physician discovered the basic microscopic lesion, the "tubercle" in the beginning of the nineteenth century. Cold abscess is formed by a collection of products of liquefaction and the reactive exudation. The cold abscess is mostly composed of serum, leucocytes, caseous material, bone debris and tubercle bacilli. Spinal TB or caries spine mainly involves the dorsoluber area. It mainly involves the anterior vertebral body in $90 \%$ cases and the arches or the pedicles and lamina in $10 \%$ only and rarely the spinal cord. It involves the end plates of adjacent vertebra and intervertebral disc space leads to wedging of the body. There may be involvement of multiple levels or skip lesions. The PCR (polymerized chain reaction) is positive in $98 \%$ cases $^{4,5,6}$

\section{MATERIAL \& METHODS}

This descriptive study was conducted in the department of neurosurgery lady reading hospital Peshawar from Jan. 2010 to Jan. 2011. Patients of all ages and sex were included in the study. Spinal osteoporosis, metastatic and pyogenic infections were excluded. Patients were diagnosed on the basis of history of localized pain in the spine and general weakness. On clinical examination localized tenderness in the spine, limbs weakness and gibbus formation or spinal deformity. In all patients were performed X-Ray chest, ESR (erythrocyte sedimentation rate), MRI spine and pus culture sensitivity in 0perated cases. All data was collected by using a proforma and analyzed by SPSS software version 17.

\section{RESULTS}

A total of 51 cases were included in the study males were $31(60.8 \%)$ and females were 20 
(39.2\%). Age was ranged from 10 to 65 years average age was 30years. Ages groups were $<12$ years $3(5.9 \%)$ cases, from 13-25 years were 4 (7.8\%) patients, from $26-40$ years were $14(27.5 \%)$ cases, from 41 to 50 years were $20(39.2 \%)$ cases and $>50$ years were $10(19.6 \%)$ patients. All patients had severe backache and local tenderness in the spine and $14(27.5 \%)$ cases had kyphotic deformities of the spine. In all cases ESR was done which was raised in all cases. X-ray chest and MRI spine were done in all cases. Cervical spine was involved in $4(7.8 \%)$ cases, upper thoracic(T1-T6) in $11(21.6 \%)$ cases, lower thoracic in $25(49 \%)$ patients, lumbar spine in $11(21.6 \%)$ cases. 13 $(25.5 \%)$ cases out of 51 had paraspinal abscess. All patients were treated with standard anti tubercular treatment (ATT) regmine, strong analgesics and supportive therapy. Abscesses were drained in 10 cases. All patients had significant outcome.

Table No 1: Age groups

\begin{tabular}{|l|c|c|c|}
\hline S.No & Age groups in years & N & $\%$ \\
\hline 1. & $<12$ & 3 & 5.9 \\
\hline 2. & $13-25$ & 4 & 7.8 \\
\hline 3. & $26-40$ & 14 & 27.5 \\
\hline 4. & $41-50$ & 20 & 39.2 \\
\hline 5. & $>50$ & 10 & 19.6 \\
\hline Total & & 51 & 100 \\
\hline
\end{tabular}

Table No 2: level of spinal involvement.?

\begin{tabular}{|c|c|c|c|}
\hline S.NO & Spinal Level & Number & \% \\
\hline 1. & Cervical & 4 & 7.8 \\
\hline 2. & Upper thoracic & 11 & 21.6 \\
\hline 3. & Lower thoracic & 25 & 49 \\
\hline 4. & Lumbar & 11 & 21.6 \\
\hline Total & & $\mathbf{5 1}$ & $\mathbf{1 0 0 \%}$ \\
\hline
\end{tabular}

\section{Table No 3: Outcome}

\begin{tabular}{|c|l|c|c|}
\hline S.No & \multicolumn{1}{|c|}{ Outcome } & Frequency & $\%$ \\
\hline 1. & Localized pain improved & 49 & 96.1 \\
\hline 2. & Localized Tenderness & 47 & 92.2 \\
\hline 3. & Limbs weakness & 46 & 90.2 \\
\hline 4. & Kyphotic deformity improved & 26 & 51.0 \\
\hline 5. & Mortality & Nil & 0 \\
\hline
\end{tabular}

\section{DISCUSSION}

Spinal tuberculosis has severe morbidity in terms of spinal deformity, neurological deficits and various degree of handicapness if not treated in early stages of the disease. In our study majority of the cases were male belongs to 3,4 and $5^{\text {th }}$ decades of life. The primary focus of tuberculosis was present in one case. In $70.6 \%$ of cases in our study involved the thoracic spine and in $21.6 \%$ cases involved the lumbar spine $e^{7,8,9,10}$. Sacral part of the vertebral column is rarely involved. In our study all cases involved the anterior part of the body and intervertebral disc space which led to the wedging of vertebra and no case was observed in which posterior elements of the vertebra i.e. the pedicles and laminae are involved. In international studies the posterior elements are involved in $10 \%$ of cases. The major signs and symptoms were localized pain and tenderness in the involved area of the spine. General symptoms like fever, weight loss, weakness and anorexia occurs are also occurs in many cases ${ }^{11,12}$. Neurological deficits like Para pareses or plegia and tetrepareses in some cases occurs when spinal cord compression occurs. The choice of investigation in case of spinal TB is MRI spine and in some cases 3D CT of the spine. In 10 cases we did spinal abscess drainage. The culture sensitivity in these cases was negative. The PCR for mycobacterium tuberculosis is positive in $90 \%$ cases in international studies. Standard ATT was given for 12 to 18 months, 4 drugs for 2 months and 3 drugs for 10 to 15 months. In this study we have not included those cases in which spinal stabilization procedures were done. All patients received strong analgesics and supportive therapy. All patients had well out come and no mortality ${ }^{13,14}$.

\section{CONCLUSION}

Spinal tuberculusis mainly affected young age group. It involved the thoracic spine in majority of cases. Easley treatable, rarely needs drainage. In advanced cases some degree of kyphotic deformity remains.

\section{REFERENCES}

1. Tuli SM. Severe kyphotic deformity in tuberculosis of spine: Current concepts. Int Orthop. 1995; 19:327-31.

2. Turgut M. Spinal tuberculosis (Pott's disease): its clinical presentation, surgical management, and outcome. A survey study on 694 patients. Neurosurg $\operatorname{Rev} 2001 ; 24: 8-13$.

3. Jain AK. Tuberculosis of the spine: a fresh look at an old disease. J Bone Joint Surg Br 2010;92:905-13. 
4. Samuel S. Comment on Oguz et al.: a new classification and guide for surgical treatment of spinal tuberculosis. Int Orthop 2010;34:613.

5. Nene A, Bhojraj S. Results of nonsurgical treatment of thoracic spinal tuberculosis in adults. Spine J 2005;5:7984.

6. Kotil K, Alan MS, Bilge T. Medical management of Pott disease in the thoracic and lumbar spine: a prospective clinical study. J Neurosurg Spine 2007;6:222-8.

7. Wang $Z, G e Z$, Jin $W$, et al. Treatment of spinal tuberculosis with ultrashort-course chemotherapy in conjunction with partial excision of pathologic vertebrae. Spine J 2007;7:671-81.

8. Pawar UM, Kundnani V, Agashe V, Nene A. Multidrugresistant tuberculosis of the spine--is it the beginning of the end? A study of twenty-five culture proven multidrug-resistant tuberculosis spine patients. Spine (Phila Pa 1976) 2009;34:E806-10.

9. Teegala R, Kumar P, Kale SS, Sharma BS. Craniovertebral junction tuberculosis: a new comprehensive therapeutic strategy. Neurosurgery 2008;63:946-55.

10. Rajasekaran S. The problem of deformity in spinal tuberculosis. Clin Orthop Relat Res 2002;(398):85-92.

11. Polley P, Dunn R. Noncontiguous spinal tuberculosis: incidence and management. Eur Spine J 2009; 18:1096101.

12. Park DW, Sohn JW, Kim EH, et al. Outcome and management of spinal tuberculosis according to the severity of disease: a retrospective study of 137 adult patients at Korean teaching hospitals. Spine (Phila $\mathrm{Pa}$ 1976) 2007;32:E130-5.

13. Turgut M. Multifocal extensive spinal tuberculosis (Pott's disease) involving cervical, thoracic and lumbar vertebrae. Br J Neurosurg 2001; 15:142-6.

14. Bakhsh A. Medical management of spinal tuberculosis: an experience from Pakistan. Spine (Phila Pa 1976) 2010;35:E787-91.

\title{
FOR CORRESPONDENCE:
}

\author{
Dr. Ali Haider \\ Consultant Neurosurgeon, \\ Post Graduate Medical Institute, \\ Lady Reading Hospital, Peshawar. \\ E.mail.haider_nvs@yahoo.com
}

